\title{
Idades U-Pb de zircão detríticos e suas implicações na proveniência de sedimentos da Formação Penedo, Bacia de Sergipe-Alagoas, NE Brasil
}

\author{
$U-P b$ dating of detrital zircon and its implications for provenance of the \\ sediments of Penedo Formation, Basin of Sergipe-Alagoas, NE Brazil
}

\author{
Alice Maria Queiroz de Melo', Maria de Lourdes da Silva Rosa¹, Herbet Conceição \\ ${ }^{1}$ Programa de Pós-Graduação em Geociências e Análises de Bacia, Universidade Federal de Sergipe - UFS, \\ Avenida Marechal Rondon, s/n, Galpão das Geociências, Sala 101 - Jardim Rosa Elze, CEP 49100-000, \\ São Cristóvão, SE, BR (alicemqm@gmail.com; Irosa@ufs.br; herbet@ufs.br)
}

Recebido em 15 de fevereiro de 2017; aceito em 07 de dezembro de 2017

\begin{abstract}
Resumo
A Formação Penedo representa um sistema fluviodeltaico de padrão entrelaçado pertencente ao estágio rifte da Bacia de Sergipe-Alagoas (BSA). Este trabalho foi realizado na seção aflorante, que deu o nome a esta unidade, localizada na cidade de Penedo, Estado de Alagoas, e denominada PDO-01. A metodologia de estudo envolveu análise de paleocorrente aliada à datação U-Pb de cristais de zircão detríticos por Espectrometria de Massa por Ablação a Laser (LA-ICP-MS). O registro sedimentar de paleocorrentes indicou aporte vindo de norte, enquanto os cristais analisados apresentaram idades variando do Mesoarqueano (3098 $\pm 33 \mathrm{Ma}$ ) ao Paleozoico (530 $\pm 12 \mathrm{Ma}$ ), que foram reunidas em cinco grupos (G1 a G5). Dessa análise conjunta foram propostas as seguintes fontes de proveniência: para o primeiro grupo (G1), os granitos neoproterozoicos ( $670 \mathrm{Ma})$ pertencentes ao Domínio Pernambuco-Alagoas; para o segundo grupo (G2), as rochas do Complexo Cabrobó ( 0,9 - 1,2 Ga); para o terceiro grupo (G3), as rochas do Complexo Arapiraca com idades paleoproterozoicas $(\sim 1,6-2,2 \mathrm{Ga})$; e para o quarto e o quinto grupos (G4 e G5), as rochas do Complexo Nicolau Campo Grande com idades neoarqueanas $(\sim 2,4-3,0 \mathrm{Ga})$.
\end{abstract}

Palavras-chave: Análise de Proveniência; Datação U-Pb; Formação Penedo; Bacia de Sergipe-Alagoas.

\begin{abstract}
The Penedo Formation represents a river-delta system of braided pattern that belongs to the rift stage of the SergipeAlagoas Basin. This work was executed on the classical outcrop section in the city of Penedo, state of Alagoas, Brazil, and named here as PDO-01. The methodology consisted of paleocurrent analysis allied to U-Pb dating of detrital zircon by laser ablation mass spectrometry. The sedimentary record of paleocurrents indicate a contribution coming from north, as the analyzed crystals yielded ages ranging from Mesoarchean $(3098 \pm 33 \mathrm{Ma})$ to Paleozoic $(530 \pm 12 \mathrm{Ma})$, that can be gathered in five groups (G1 to G5). From this analysis, the following sources were proposed: for the first group (G1), Neoproterozoic granites ( $670 \mathrm{Ma}$ ) from the Pernambuco-Alagoas Domain; for the second group (G2), the rocks of the Cabrobó Complex ( $\sim 0.9-1.2 \mathrm{Ga})$; for the third group (G3), the rocks of the Arapiraca Complex with Paleoproterozoic ages $(\sim 1.6-2.2 \mathrm{Ga})$; and for the fourth and fifth groups (G4 and G5), the rocks of the Nicolau Campo Grande Complex, with Neoarquean ages $(\sim 2.4-3.0 \mathrm{Ga})$.
\end{abstract}

Keywords: Provenance Analysis; U-Pb Dating; Penedo Formation; Sergipe-Alagoas Basin. 


\section{INTRODUÇÃO}

A análise de proveniência em sedimentos tem a finalidade de restaurar as relações existentes entre as áreas-fonte e suas bacias sedimentares, sobretudo por meio da identificação e da localização das rochas fontes. Para tanto, diversas técnicas podem ser aplicadas, tais como a identificação da composição dos plagioclásios detríticos em arenitos; a identificação dos tipos de maclas nos feldspatos ou tipos de grãos de quartzo e suas inclusões; a análise de minerais pesados; a análise geocronológica; o levantamento de paleocorrente; e a identificação de seixos e calhaus em arenitos conglomeráticos e conglomerados (Roback e Walker, 1995; Morton et al., 1996, 2005; Sircombe, 1999, 2000; Carwood e Nemchin, 2000; Hallsworth et al., 2000; Link et al., 2005; Nascimento et al., 2007; Araújo et al., 2012; Neves, 2015).

A chamada "análise convencional de minerais pesados detríticos" consiste na determinação da composição de toda a assembleia de minerais pesados presentes nos sedimentos (Morton e Hallsworth, 1994), que é consideravelmente influenciada pela intensidade do intemperismo ocorrido na área-fonte e pelo transporte; pelo nível de abrasão ao qual os sedimentos são submetidos durante o percurso; pela seleção hidrodinâmica no momento da deposição; e pela diagênese (Morton, 1985; Johnsson, 1993; Morton e Hallsworth, 1994).

A seleção hidráulica ocorrida durante a deposição e os processos diagenéticos é o fator que mais modifica a composição final dos sedimentos (Morton, 1985), mas pode ser contornada por meio do estudo das variabilidades, sejam geocronológicas, químicas ou morfológicas, dentro de uma população mineral. Isso porque as variações de quaisquer características presentes em uma população de minerais são herdadas diretamente da fonte e não resultam do fracionamento durante o ciclo sedimentar (Johnsson, 1993). Segundo Mange e Morton (2007), o estudo das variabilidades aumenta a certeza e insere detalhes não avaliados em análises convencionais de minerais pesados. A geocronologia utilizando U-Pb em zircão detrítico é a mais usual e poderosa técnica para extrair informação da fonte, visto que provê dados sobre a fonte inicial dos sedimentos, e não sobre a fonte sedimentar reciclada (Fedo et al., 2003).

A Bacia de Sergipe-Alagoas (BSA) é uma das muitas bacias da margem continental, formada durante a abertura do Atlântico Sul, no final do Jurássico e Eocretáceo (Souza-Lima et al., 2002). Limita-se ao norte com a Bacia de Pernambuco-Paraíba, pelo alto de Maragogi, e ao sul com a Bacia de Jacuípe, pela Falha do Vaza Barris (Matos, 1999). A Formação Penedo, incluída na BSA, pertence à supersequência rifte e compreende os arenitos de granulação grossa a média, de ambiente fluviodeltaico, com retrabalhamento eólico (Schaller, 1970; Souza-Lima et al., 2002; Campos Neto et al., 2007).
Apesar de a BSA ser uma bacia bastante estudada, pesquisas de proveniências utilizando-se de geocronologia de zircão são escassas (Santos, 2015; Almeida, 2016). Este estudo, baseado em análises geocronológicas U-Pb, com Espectrometria de Massa por Ablação a Laser (LA-ICP-MS), de cristais de zircão detríticos, associadas à análise de paleocorrentes, teve como objetivo identificar as prováveis áreas-fonte dos arenitos do afloramento clássico da Formação Penedo (PDO-01), Estado de Alagoas (Figura 1). A identificação das fontes dos arenitos da Formação Penedo permitirá melhorar a compreensão sobre os eventos ocorridos durante a evolução da BSA, sobretudo durante o Andar Rio da Serra, início da fase rifte, em que o afloramento está estratigraficamente posicionado. Esses são os primeiros dados geocronológicos obtidos para esse setor da BSA.

\section{CONTEXTO GEOLÓGICO}

A Formação Penedo da BSA situa-se em um contexto regional que inclui terrenos geológicos de diferentes idades e ambiências tectônicas. Em virtude das paleocorrentes levantadas na seção estudada PDO-01, o contexto geológico de interesse abrange parte dos Estados de Alagoas e Pernambuco, ao norte do afloramento (Figura 2).

\section{Embasamento}

O embasamento nessa região (Mendes et al., 2009) inclui: os terrenos arqueanos (Domo do Jirau do Ponciano); a porção sudeste do Domínio Pernambuco-Alagoas; o Domínio Rio Coruripe; e a porção norte do Sistema Orogênico Sergipano (domínios Macururé e Canindé). Essas unidades estão incluídas na porção meridional da Província Borborema (Hasui et al., 2012).

O embasamento arqueano é representado pelos Complexos Jirau do Ponciano e Nicolau Campo Grande e pelo ortognaisse Serra das Cabaças, que, juntos, compreendem o Domínio Jirau do Ponciano (Figura 2), cuja característica é a ausência de intrusões neoproterozoicas (Figura 2). O Complexo Jirau do Ponciano é composto por ortognaisses tonalíticos a graníticos e compreende o núcleo do anticlinal de Jirau do Ponciano, um dobramento isoclinal invertido, com caimento do eixo para oeste e mergulho da superfície axial para sul (Brito e Mendes, 2011). O Complexo Nicolau Campo Grande é composto por gnaisses quartzo-feldspáticos que ocorrem em duas associações litológicas distintas: uma dominada por metassedimentos químicos, metamáficas, metaultramáficas e formação ferrífera bandada, e outra dominada por rochas metassedimentares (Mendes, 2010). O ortognaisse Serra das Cabaças compreende metagranitos tipo S, constituindo ortognaisses com aspecto porfiroide (Amorim, 1995); localmente podem conter xenólitos de supracrustais 
(Mendes et al., 2015). Brito Neves (1986), para amostras dessa unidade, obteve idades $\mathrm{Rb}-\mathrm{Sr}$ convencionais de 2,1 e 2,3 Ga (riacianas). Para as rochas dos Complexos Nicolau Campo Grande e Jirau do Ponciano são atribuídas idades arqueanas/paleoproterozoicas, visto que essas ocorrem como xenólitos no ortognaisse Serra das Cabaças (Mendes, 2010).

O Domínio Rio Coruripe (Amorim, 1995) está limitado a norte com a Zona de Cisalhamento Palmeira dos Índios, que o separa do Domínio Pernambuco-Alagoas. A oeste, encontra-se sotoposto aos representantes do Domínio Canindé (Complexo Araticum), e a sul, está parcialmente recoberto, discordantemente, pelos metassedimentos do Domínio Macururé. Esse domínio é representado pelo Complexo Arapiraca, composto por granitos mesoproterozoicos indiscriminados e granitos neoproterozoicos raros (Brito e Mendes, 2011). O Complexo Arapiraca compreende paragnaisses bandados, frequentemente migmatizados e, por vezes, granulitizados. Contém intercalações de lentes e/ou camadas de rochas metamáficas, mármores dolomíticos, rochas calcissilicáticas, formações ferríferas bandadas, quartzitos e complexos ígneos de metamáficas-metaultramáficas (Mendes, 2010). Brito et al. (2005) obtiveram em metaultramáficas duas idades U-Pb (em zircão), uma de 1965 Ma e outra, para zircão herdado, de 2049 Ma. Cristais de zircão extraídos do leucossoma de migmatito do Complexo Arapiraca possuem idades em torno de 760 e $630 \mathrm{Ma}$ (Lima, 2013), sendo os mais novos possivelmente relacionados ao evento Brasiliano que atuou na Província Borborema no período de 750 - $560 \mathrm{Ma}$ (Oliveira et al., 2010, 2015).

O Domínio Pernambuco-Alagoas está limitado ao sul pela Zona de Cisalhamento Palmeira dos Índios e ao norte pela Zona de Cisalhamento Pernambuco. É formado pelo Complexo Belém do São Francisco, Granitos Indiscriminados Mesoproterozoicos, Complexo Cabrobó, Suíte Intrusiva Leucocrática Peraluminosa, Ortognaisse Serra das Flores e diversas intrusões graníticas do Neoproterozoico/Ediacarano (Suítes Intrusivas Ouro Branco, Itaporanga, Serra do Catu e granitoides indiscriminados) e do Paleozoico/Cambriano (Suíte Intrusiva Águas Belas) (Figura 2). O Complexo Belém do São Francisco é composto por ortognaisse granítico a tonalítico-granodiorítico, eventualmente migmatizado, com enclaves máficos de composição quartzo-diorítica e enclaves de rochas supracrustais (Mendes et al., 2015). Dados U-Pb (SHRIMP) em zircão forneceram idade 2079 \pm 34 Ma para cristalização de protólito de ortognaisse do Complexo Belém do São Francisco e de $655 \pm 7$ Ma para seu metamorfismo

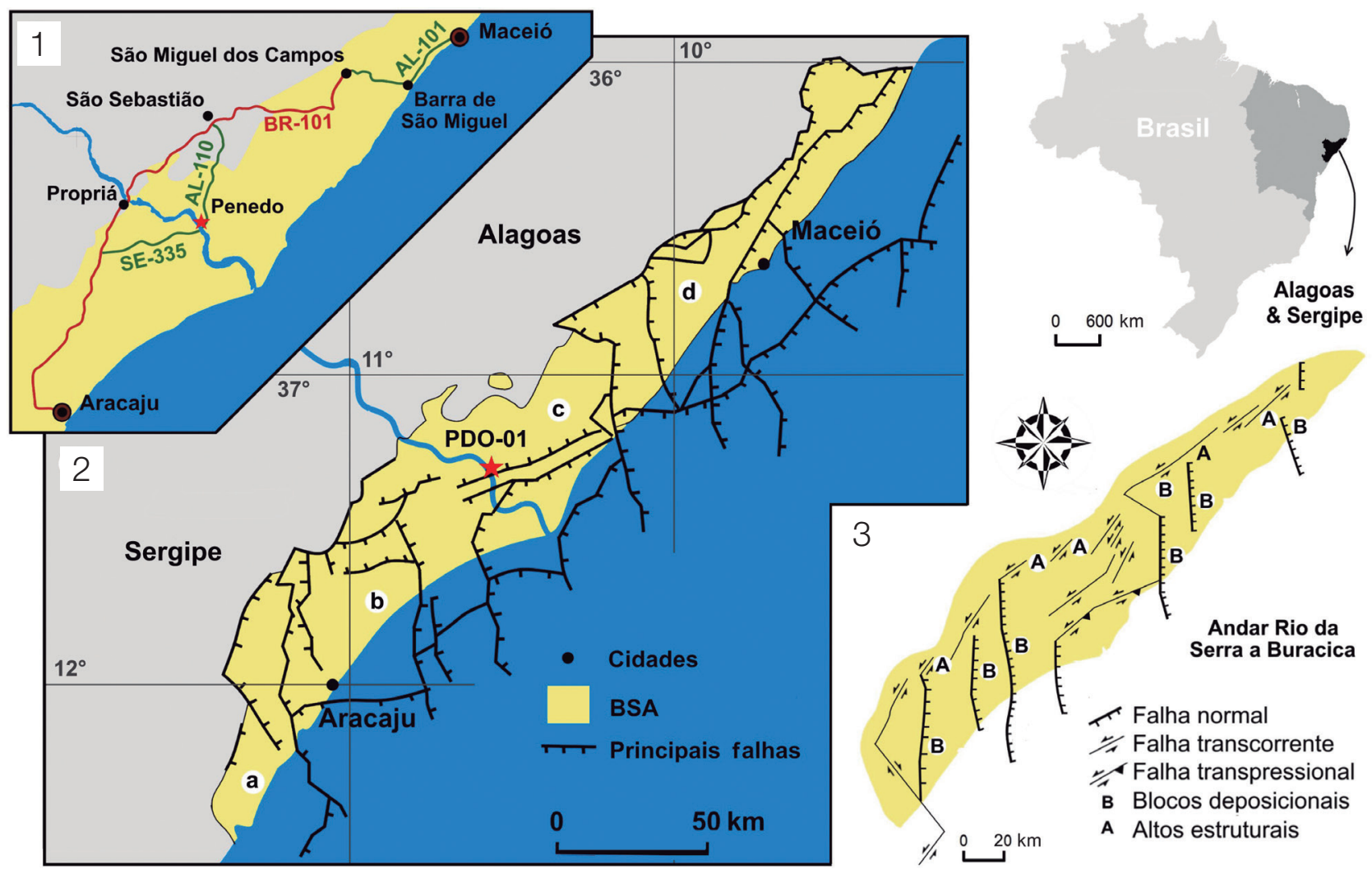

1: vias de acesso; 2: principais estruturas da Bacia de Sergipe-Alagoas (Mohriak, 1998); a: Plataforma de Estância; b: Plataforma de Sergipe; c: Alto de JapoatãPenedo; d: Baixo de Alagoas; 3: principais estruturas definidas para o Andar Rio da Serra (Lana, 1985); seção aflorante PDO-01 representada por estrela vermelha, localizada na cidade de Penedo, estado do Alagoas; BSA: Bacia de Sergipe-Alagoas.

Figura 1. Mapa de localização, vias de acesso e principais estruturas da Bacia de Sergipe-Alagoas. 
(Silva Filho et al., 2002). O Complexo Cabrobó compreende uma sequência metavulcanossedimentar formada por xistos e paragnaisses eventualmente migmatizados, metagrauvacas, quartzitos, calcissilicáticas, mármores e intercalações de metamáficas. Dados geocronológicos para esse complexo incluem idade $\mathrm{Rb}$-Sr isocrônica de $966 \pm 14 \mathrm{Ma}$ (Brito Neves et al., 1995). Gnaisse migmatítico com granada, do subdomínio Água-Branca, foi datado em $1577 \pm 73 \mathrm{Ma}$ (Van Schmus

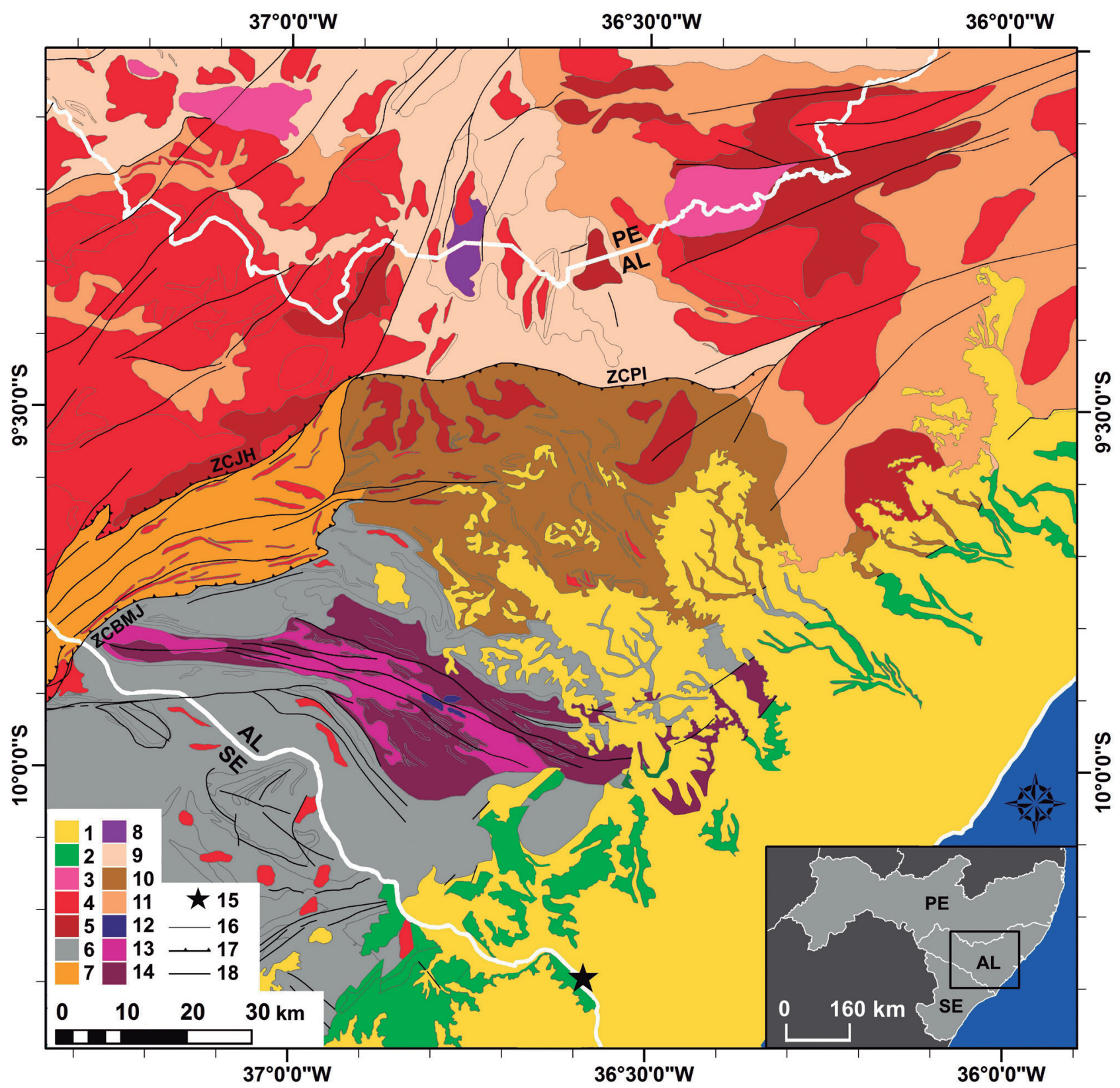

ZCBMJ: Zona de Cisalhamento Belo Monte Jeremoabo; ZCJH: Zona de Cisalhamento Jacaré dos Homens; ZCPI: Zona de Cisalhamento Palmeira dos Índios; AL: Alagoas; PE: Pernambuco; SE: Sergipe.

Fonte: modificado de Mendes et al. (2009).

Figura 2. Mapa geológico regional. Convenções: (1) Formação Barreiras e coberturas quaternárias; (2) Bacia de Sergipe-Alagoas; (3) Suíte Intrusiva Águas Belas; (4) corpos intrusivos neoproterozoicos; (5) corpos intrusivos mesoproterozoicos; (6) Domínio Macururé; (7) Complexo Araticum; (8) Ortognaisse Serra das Flores; (9) Complexo Cabrobó; (10) Complexo Arapiraca; (11) Complexo Belém do São Francisco; (12) Ortognaisse Serra das Cabaças; (13) Complexo Jirau do Ponciano; (14) Complexo Nicolau Campo Grande; (15) seção aflorante PDO-01; (16) contatos; (17) falha de empurrão; (18) falhas e fraturas. 
et al., 1995). A Suíte Intrusiva Leucocrática Peraluminosa engloba representantes de plutonismo mesoproterozoico e neoproterozoico (Medeiros, 2000). Os ortognaisses Serra das Flores são rochas que intrudem o Complexo Cabrobó e possuem idades U-Pb em zircão tonianas (947 Ma) (Mendes et al., 2011). Outras idades U-Pb para granitos do Domínio Pernambuco-Alagoas variaram de 570 a $625 \mathrm{Ma}$ (Silva Filho et al., 1997, 2000; Neves et al., 2008).

O Domínio Canindé (Davison e Santos, 1989) é parte do Sistema Orogênico Sergipano, que se consolidou durante a Orogênese Brasiliana/Pan-Africana, com a colisão entre o Cráton São Francisco e o Bloco Pernambuco-Alagoas. Está limitado ao norte pelo Domínio Pernambuco-Alagoas, por meio da Zona de Cisalhamento de Jacaré dos Homens e por intrusões graníticas neoproterozoicas (Suíte Intrusiva Serra do Catu). Ao sudeste, limita-se com os Domínios Rio Coruripe e Macururé, pela Zona de Cisalhamento Transpressional de Belo Monte-Jeremoabo. A parcela do domínio localizada no sul de Alagoas é representada pelo Complexo Araticum, que constitui uma sequência metavulcanossedimentar polideformada, metamorfisada na fácies anfibolito, composta por micaxisto, biotita gnaisse, metagrauvaca, metamáficas, metaultramáficas, formações ferríferas, mármores, quartzitos e calcissilicáticas (Lima, 2013). Silva Filho et al. (2003), por meio de análises isotópicas de carbono e oxigênio em amostra de mármore dessa unidade, dataram a sedimentação do protólito entre 1,05 e 1,20 Ga. Idades de $611 \mathrm{Ma}$ (U-Pb em zircões) foram obtidas de leucogranito a duas micas (Brito e Mendes, 2011).

\section{Bacia de Sergipe-Alagoas}

Apesar de a BSA ser tratada como uma bacia única, as Sub-Bacias de Sergipe e de Alagoas possuem cartas estratigráficas distintas devido às diferenças de estilo tectônico e preenchimento, e estão separadas por um alto regional localizado na área do Rio São Francisco (Mohriak et al., 1998), denominado Alto de Japoatã-Penedo (Figura 1). $\mathrm{O}$ preenchimento sedimentar neopaleozoico e jurássico apresenta grande similaridade ao longo das duas sub-bacias. No entanto, os andares Rio da Serra e Aratu, contendo a Formação Penedo, estão mais desenvolvidos na Sub-Bacia de Alagoas, enquanto as unidades mais recentes adquirem importância maior na Sub-Bacia de Sergipe (Feijó, 1995).

A porção emersa da BSA é representada por uma estreita faixa, de 20 a $50 \mathrm{~km}$ de largura, e a sua maior parte está submersa (Souza-Lima et al., 2002). Essa bacia é caracterizada pela existência de um pacote sedimentar relativamente fino em terra e por uma série de depocentros controlados por falhas sintéticas, que formam grábens assimétricos (Mohriak et al., 1997). O quadro estrutural da BSA (Figura 1) está associado com um sistema de falhas normais NE-SW e falhas secundárias transversais E-W e NW-SE (Mohriak et al., 1998).
O preenchimento sedimentar da BSA é representado por 23 sequências deposicionais correlacionáveis aos estágios evolutivos termomecânicos que ocorreram nas bacias da margem leste brasileira (Campo Neto et al., 2007). Os limites entre os estágios - sinéclise, pré-rifte, rifte e drifte — refletem as modificações no estilo tectônico predominante que afetou as sequências sedimentares (Souza-Lima et al., 2002).

\section{Formação Penedo}

A Formação Penedo pertence ao estágio rifte da BSA, que corresponde à fase de subsidência mecânica da bacia. Essa fase iniciou-se há aproximadamente $142 \mathrm{Ma}$, no Andar Rio da Serra (Feijó, 1995), favorecida pelo aumento da taxa de subsidência (Campos Neto et al., 2007) (Figura 3). Os sedimentos dessa unidade foram depositados durante intensa atividade tectônica, que precedeu a abertura do Oceano Atlântico. As rochas dessa fase mostram grandes variações laterais de fácies e espessura, como resultado da atuação das falhas de borda da bacia.

Em acordo com Campos Neto et al. (2007), o contato inferior da Formação Penedo com a Formação Feliz Deserto pode ser gradacional ou discordante, enquanto o contato superior, com as Formações Poção, Morro do Chaves e Coqueiro Seco, é discordante (Figura 3). Lateralmente, em sua porção distal, interdigita-se com a Formação Barra de Itiúba. Na parte sergipana da bacia, a Formação Penedo interdigita-se lateralmente, em sua porção proximal, com os arenitos e conglomerados de borda ativa da Formação Rio Pitanga (Souza-Lima, 2008a).

Segundo Schaller (1970), a Formação Penedo é constituída por espessos leitos de arenitos mal selecionados, finos a grossos, subangulares a subarredondados, com intercalações de folhelhos e siltitos (Figura 4). Com coloração branca, cinzenta, amarelada e localmente esverdeada ou avermelhada, contém pontilhados brancos provenientes da alteração de feldspato, característico dessa formação. Os arenitos são puros a argilosos, muitas vezes contendo mica. Ocorrem também subarcósios, arcósios, com presença de feldspato, muitas vezes caulinizados, além de mica e fragmentos líticos (Vieira, 1991). Os folhelhos, em parte micáceos, variam de verde, cinza e castanho a avermelhado, quando próximo à borda da bacia $\mathrm{e}$ junto à Formação Rio Pitanga. Localmente podem ocorrer calcários argilosos impuros de cor creme acinzentado. Também ocorrem lentes de conglomerado, interpretados por Schaller (1970) como marcadores do assoalho de canal fluvial.

A geometria dos corpos arenosos varia de tabular a sigmoidal, exibindo também grandes canais. São comuns estratificações tabulares e tangenciais, muitas vezes com sets superiores a $50 \mathrm{~cm}$ de espessura, e feições acanaladas com largura de leito da ordem de dezenas de metros (Schaller, 1970). Também são comuns estruturas convolutas (Figura 4) relacionadas à fluidização (Souza-Lima, 2008b). 


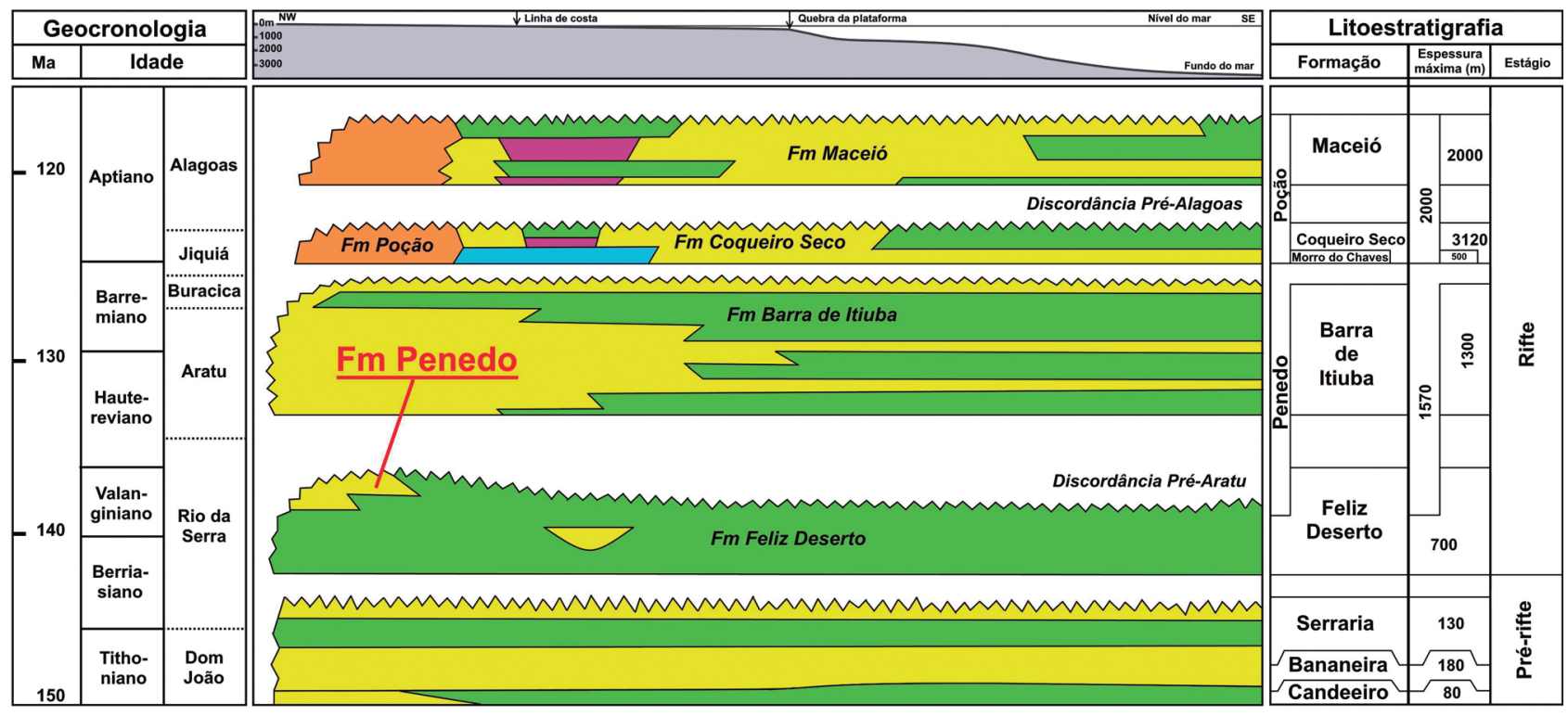

Figura 3. Fração da Carta estratigráfica da Sub-Bacia de Alagoas, com destaque para a Formação Penedo (Campos Neto et al., 2007).
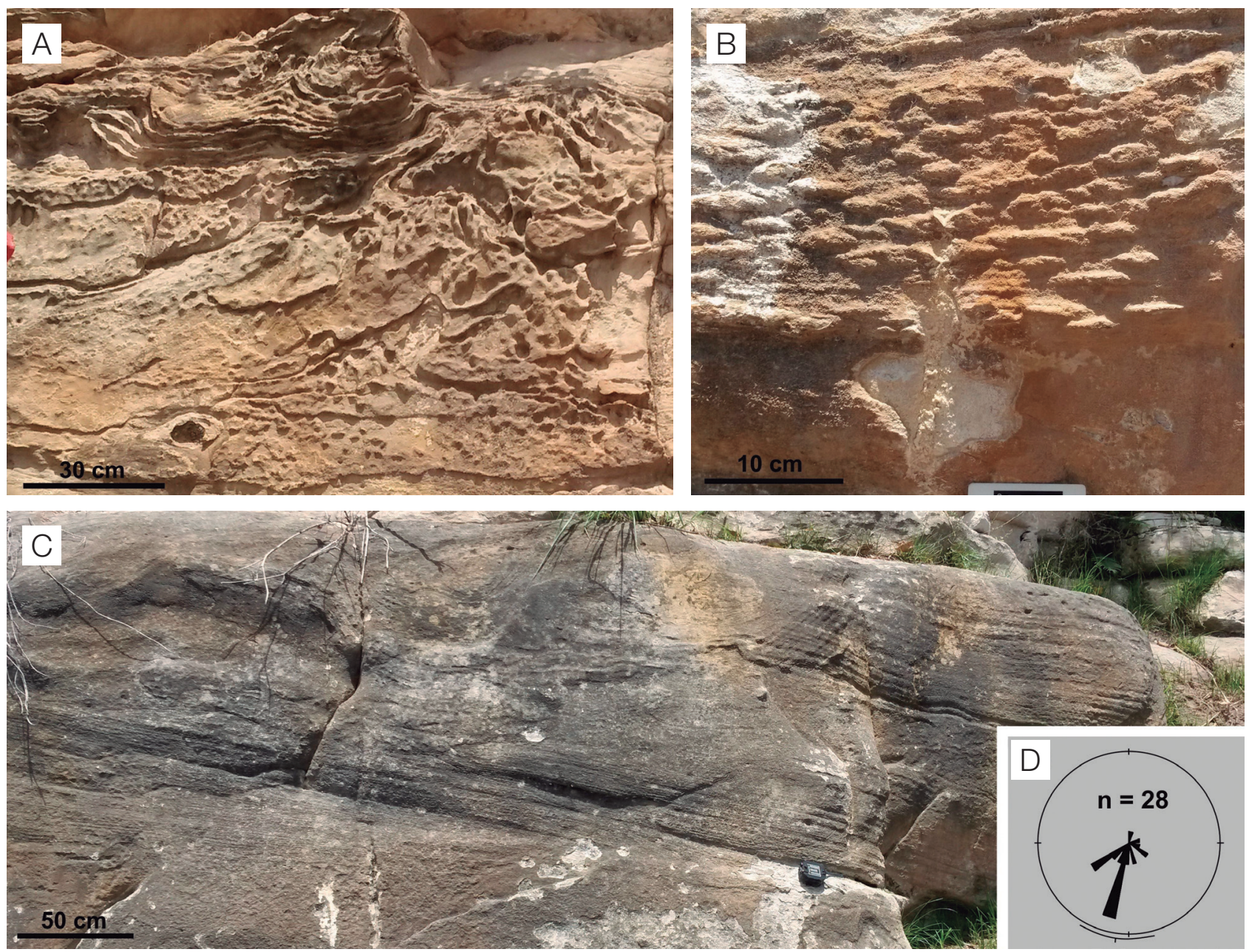

Figura 4. Fotos de partes da seção PDO-01. Arenitos da Formação Penedo apresentando: (A) estruturas de fluidização; (B) climb ripples; (C) estratificações cruzadas; (D) 28 medidas de paleocorrente. 
Em relação aos ambientes deposicionais, o registro sedimentar aponta para um sistema fluviodeltaico de padrão entrelaçado (Vieira, 1991) que desembocava nos sedimentos prodeltaicos e lacustres que atualmente constituem a Formação Barra de Itiúba. A atuação de rios entrelaçados e deltas foi bem desenvolvida, formando, no todo, um sistema progradante (Feijó, 1995). O padrão de drenagem aparentemente foi transversal ao sistema lacustre, conforme indicam as medidas de paleocorrentes obtidas por Souza-Lima e Borba (2008).

A seção aflorante PDO-01 constitui um paredão rochoso de aproximadamente $20 \mathrm{~m}$. É composta por arenitos finos a médios, de coloração amarela, por vezes com algum conteúdo silticoargiloso esbranquiçado. Apresenta geometria tabular e sigmoidal, contendo estratificações cruzadas e climb ripples, estratificações plano-paralelas e quantidade considerável de estruturas de fluidização (Figura 4). Nesse local, foram aferidas 28 medidas de paleocorrente de estratificações cruzadas, cuja média indica direção $187,9^{\circ} \mathrm{e}$ confiabilidade de 23,4 (Figura 4), corroborando dados das referências bibliográficas (Souza-Lima, 2008b), segundo os quais os aportes teriam sido para S-SE na região dos altos de Japoatã (Sergipe) e Palmeira Alta (Alagoas) durante o Andar Rio da Serra ( 140 Ma).

\section{METODOLOGIA}

Após selecionar o afloramento-chave da Formação Penedo (Seção PDO-01), foram realizadas a coleta de amostra e a análise de paleocorrente. Os cristais de zircão foram concentrados por meio de metodologia clássica: redução da granulação com britador; quarteamento; cominuição na fração menor que 60 mesh; concentração de minerais pesados com uso de bateia; separação de cristais não magnéticos utilizando-se do separador isodinâmico Frantz; posteriormente, o concentrado de minerais obtidos foi passado em líquidos densos (bromofórmio e diodometano). Por fim, os cristais de zircão foram catados manualmente com o auxílio de lupa binocular, de forma randômica, e encaminhados para confecção de mount e metalização com ouro. Esses procedimentos foram realizados no Centro de Pesquisa Geocronológica da Universidade de São Paulo (CPGeo-USP), segundo metodologia descrita em Araújo et al. (2012).

As determinações geocronológicas foram realizadas no CPGeo-USP, utilizando-se de Espectrometria de Massa por Ablação a Laser (LA-ICP-MS), marca Finnigan Neptune, acoplado a ArF Laser. Durante as análises, foram escolhidos pontos em zonas oscilatórias primárias, típicas de texturas ígneas em cristais de zircão. Além disso, foram evitados cristais muito fraturados e com inclusões. Alguns grãos tiveram mais de um spot, no intuito de verificar se existiam diferenças de idade entre o centro do cristal e sua margem.
Os dados foram processados com software Isoplot (Ludwig, 2012). As incertezas para os índices medidos são dados em nível de um (1) sigma. Idades menores que 1.300 Ma são referidas como idades ${ }^{206} \mathrm{~Pb} /{ }^{238} \mathrm{U}$ e idades maiores que $1300 \mathrm{Ma}$, como idades ${ }^{207} \mathrm{~Pb} /{ }^{235} \mathrm{U}$. Os dados estão apresentados por meio de tabela, em diagrama de concórdia e em diagrama de frequência e curva de probabilidade. Foram obtidas imagens de catodoluminescência dos cristais datados, com MEV (Hitachi S-2250N) sob condições de aceleração de voltagem de $20 \mathrm{kV}$.

\section{RESULTADOS E DISCUSSÕES}

Para datação U-Pb, foi selecionada a amostra PDO-01 da Formação Penedo. Do concentrado de cristais de zircão dessa amostra, foram investigados 83 cristais de zircão e 90 spots, dos quais 64 foram utilizados para análise geocronológica (Tabela 1). Os resultados são apresentados graficamente na forma de histograma de densidade e frequência das idades U-Pb (Figura 5) e na forma de diagrama concórdia $\mathrm{Pb}^{206} / \mathrm{U}^{238}$ versus $\mathrm{Pb}^{207} / \mathrm{U}^{235}$ (Figura 6). Foram utilizadas apenas análises com concordância de 100 $\pm 10 \%$. As idades obtidas apresentam uma concordância média de 99,7\% (Tabela 1).

Os grãos de zircão detríticos analisados apresentam dimensões que variam de 150 a $350 \mu \mathrm{m}$. Não foi possível observar correlação entre as idades dos grãos e sua morfologia (Figura 5). Com exceção do grupo mais antigo, há presença de grãos mais arredondados ou subarredondados em todos os grupos de idade, o que pode estar relacionado ao maior transporte e a fontes mais distantes ou mesmo ao retrabalhamento. No entanto, a maioria dos cristais detríticos ainda preserva feições que indicam cristais de formato prismático.

Os concentrados de zircão da amostra PDO-01 apresentam idades que variam desde o Mesoarqueano (3098 \pm

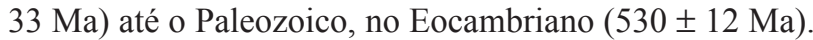
Metade dessas idades está acima de $1300 \mathrm{Ma}$. No histograma de densidade e frequência (Figura 6) é possível distinguir cinco grupos de idades, nomeados de G1 a G5, em ordem geocronológica crescente.

O Grupo 1 - G1 (Figura 5) compreende os cristais mais jovens, com idades que variam de 518 a $691 \mathrm{Ma}$. Um total de $21,9 \%$ das análises está nesta população, com concordância média de $99,8 \%$. A maioria desses cristais tem idade criogeniana (neoproterozoica), mas chegam a alcançar idades paleozoicas, do Eocambriano. O maior pico da curva de probabilidade encontra-se em aproximadamente $670 \mathrm{Ma}$. Cristais do G1 apresentam zoneamento oscilatório típico de cristais ígneos. Em alguns deles, é possível observar núcleos herdados, além de sobrecrescimento por sector zonning típicos de crescimento metamórfico e corrosão da 
borda. As razões Th/U dos spots analisados variam de 0,09 a 2,00, com média de 0,69 (Tabela 1).

Considerando que a análise de paleocorrentes do local em que foi retirada a amostra indica fontes posicionadas ao norte (Figura 4), essas idades sugerem como prováveis fontes para esses cristais rochas ígneas do Complexo Araticum, como o leucogranito de $611 \mathrm{Ma}$ (Brito e Mendes, 2011) e o ortognaisse de $642 \pm 3 \mathrm{Ma}$ (Lima, 2013), além de outros corpos de granitos, como a Suíte Intrusiva Águas Belas, datada de $528 \pm 4 \mathrm{Ma}$ (U-Pb; Mendes et al., 2015); as suítes intrusivas Serra dos Macacos e Ferreira Costa; os plutons Munguba, Carneiros, Ouro Branco, Santana do Ipanema e Serra da Caatinga Branca; e outros corpos graníticos indiscriminados, datados entre 570 a 625 Ma (Silva Filho et al.,
1997, 2000). A Suíte Intrusiva Águas Belas é a única intrusão ígnea cambriana identificada ao norte da seção aflorante (Figura 2).

O Grupo 2 - G2 (Figura 5) possui cristais com idades variando de 840 a $1294 \mathrm{Ma}$, distribuídas entre o Esteniano e o Toniano. Essas idades apresentam uma concordância média de $100,0 \%$ e representam $28,1 \%$ das análises. O maior pico da curva de probabilidade encontra-se aproximadamente em $1000 \mathrm{Ma}$, no limite do Mesoproterozoico para o Neoproterozoico (Figura 6). As razões $\mathrm{Th} / \mathrm{U}$ dos spots analisados variam de $0,10 \mathrm{a}$ 1,06 , com média de 0,51 .

A maioria desses cristais (G2) apresenta zoneamento oscilatório e texturas de crescimento metamórfico, com a presença de zonas sinuosas de alta e baixa luminescência,

Tabela 1. Idades U-Pb em zircão, de acordo com os agrupamentos de idades.

\begin{tabular}{|c|c|c|c|c|c|c|c|c|c|c|c|c|c|}
\hline Grupo & $\begin{array}{c}\text { I } \\
206 / 238\end{array}$ & $1 \sigma$ & $\begin{array}{c}\text { I } \\
207 / 235\end{array}$ & $1 \sigma$ & Conc & $\mathrm{Th} / \mathrm{U}$ & Grupo & I206/238 & $1 \sigma$ & $\begin{array}{c}\text { I } \\
207 / 235\end{array}$ & $1 \sigma$ & Conc & Th/U \\
\hline \multirow{14}{*}{ G1 (21,9\%) } & 530 & 12 & 524 & 41 & 101 & 2,00 & \multirow{27}{*}{ G3 $(42,2 \%)$} & 1637 & 26 & 1623 & 32 & 100 & 1,19 \\
\hline & 532 & 22 & 526 & 53 & 101 & 0,89 & & 1724 & 21 & 1715 & 26 & 100 & 0,32 \\
\hline & 540 & 08 & 534 & 18 & 101 & 0,48 & & 1715 & 15 & 1731 & 17 & 099 & 0,55 \\
\hline & 584 & 08 & 592 & 21 & 098 & 0,44 & & 1716 & 22 & 1738 & 26 & 098 & 0,74 \\
\hline & 587 & 08 & 581 & 20 & 101 & 0,40 & & 1793 & 21 & 1773 & 31 & 101 & 0,68 \\
\hline & 608 & 13 & 601 & 19 & 101 & 0,87 & & 1795 & 33 & 1796 & 37 & 099 & 0,81 \\
\hline & 624 & 10 & 613 & 26 & 101 & 1,61 & & 1835 & 51 & 1841 & 56 & 099 & 0,65 \\
\hline & 630 & 09 & 633 & 22 & 099 & 0,09 & & 1916 & 31 & 1872 & 30 & 102 & 0,86 \\
\hline & 655 & 08 & 654 & 19 & 100 & 0,56 & & 1855 & 18 & 1923 & 26 & 096 & 0,69 \\
\hline & 664 & 11 & 669 & 27 & 099 & 0,47 & & 1998 & 37 & 2010 & 25 & 099 & 0,96 \\
\hline & 666 & 16 & 674 & 43 & 098 & 0,64 & & 1983 & 66 & 2024 & 66 & 097 & 0,93 \\
\hline & 677 & 07 & 666 & 14 & 101 & 0,77 & & 2060 & 17 & 2036 & 19 & 101 & 0,32 \\
\hline & 680 & 08 & 689 & 16 & 098 & 0,14 & & 1989 & 24 & 2050 & 27 & 097 & 0,82 \\
\hline & 682 & 09 & 692 & 19 & 098 & 0,37 & & 1992 & 22 & 2056 & 26 & 096 & 0,83 \\
\hline \multirow{18}{*}{ G2 $(28,1 \%)$} & 853 & 13 & 846 & 29 & 100 & 0,80 & & 2070 & 41 & 2079 & 27 & 099 & 1,25 \\
\hline & 899 & 14 & 924 & 26 & 097 & 0,42 & & 2154 & 22 & 2092 & 28 & 102 & 1,21 \\
\hline & 912 & 20 & 901 & 44 & 101 & 0,27 & & 2088 & 17 & 2121 & 24 & 098 & 0,22 \\
\hline & 962 & 19 & 964 & 39 & 099 & 0,53 & & 2132 & 22 & 2128 & 21 & 100 & 0,35 \\
\hline & 978 & 17 & 967 & 36 & 101 & 0,61 & & 2182 & 59 & 2131 & 51 & 102 & 0,38 \\
\hline & 987 & 16 & 978 & 31 & 100 & 0,10 & & 2201 & 41 & 2138 & 25 & 102 & 0,67 \\
\hline & 1000 & 11 & 985 & 20 & 101 & 1,06 & & 2140 & 21 & 2158 & 20 & 099 & 0,44 \\
\hline & 1014 & 13 & 1035 & 24 & 097 & 0,84 & & 2179 & 49 & 2161 & 31 & 100 & 0,57 \\
\hline & 1016 & 15 & 1023 & 29 & 099 & 0,42 & & 2174 & 18 & 2164 & 17 & 100 & 0,49 \\
\hline & 1019 & 17 & 1006 & 27 & 101 & 0,97 & & 2235 & 21 & 2166 & 20 & 103 & 0,23 \\
\hline & 1030 & 13 & 1023 & 31 & 100 & 0,54 & & 2155 & 40 & 2168 & 25 & 099 & 0,47 \\
\hline & 1059 & 13 & 1045 & 29 & 101 & 0,15 & & 2229 & 33 & 2176 & 33 & 102 & 0,52 \\
\hline & 1083 & 18 & 1100 & 34 & 98 & 0,46 & & 2192 & 26 & 2211 & 24 & 099 & 0,36 \\
\hline & 1088 & 16 & 1070 & 24 & 101 & 0,81 & \multirow{4}{*}{ G4 (6,3\%) } & 2478 & 39 & 2535 & 21 & 097 & 0,51 \\
\hline & 1090 & 12 & 1069 & 22 & 101 & 0,15 & & 2498 & 39 & 2545 & 21 & 098 & 0,53 \\
\hline & 1234 & 20 & 1225 & 34 & 100 & 0,32 & & 2693 & 28 & 2658 & 25 & 101 & 0,48 \\
\hline & 1259 & 15 & 1247 & 22 & 101 & 0,44 & & 2733 & 48 & 2682 & 24 & 101 & 0,84 \\
\hline & 1280 & 14 & 1251 & 20 & 102 & 0,38 & G5 (1,6\%) & 2957 & 23 & 3042 & 20 & 097 & 0,48 \\
\hline
\end{tabular}

| 206/238: idades ${ }^{206} \mathrm{~Pb} /{ }^{238} \mathrm{U}$, em milhões de anos; I 207/235: idades ${ }^{207} \mathrm{~Pb} / 235 \mathrm{U}$, em milhões de anos; Conc: concordância. 
zonas oscilatórias primárias borradas e sector zoning. O cristal datado de $962 \mathrm{Ma}$ (Figura 5) apresenta-se metamórfico de alto grau, uma vez que possui típica sequência contendo uma zona inicial de baixa luminescência no interior do grão, seguido de sobrecrescimento por sector zonning e zoneamento oscilatório.

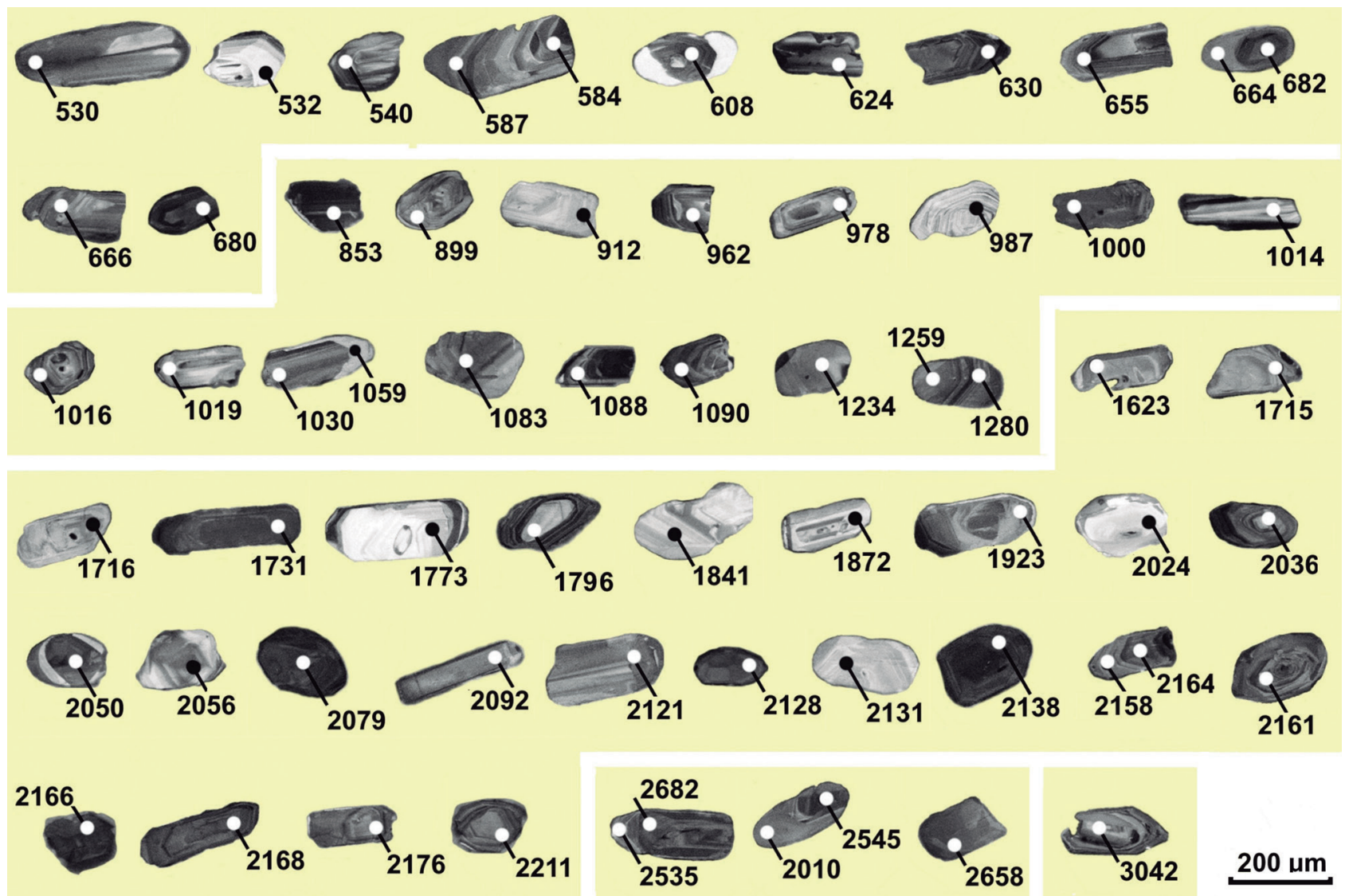

Figura 5. Imagens de catodoluminescência dos cristais de zircão analisados. Pontos brancos ou pretos representam os spots analisados; linha branca divide os grupos de idades.
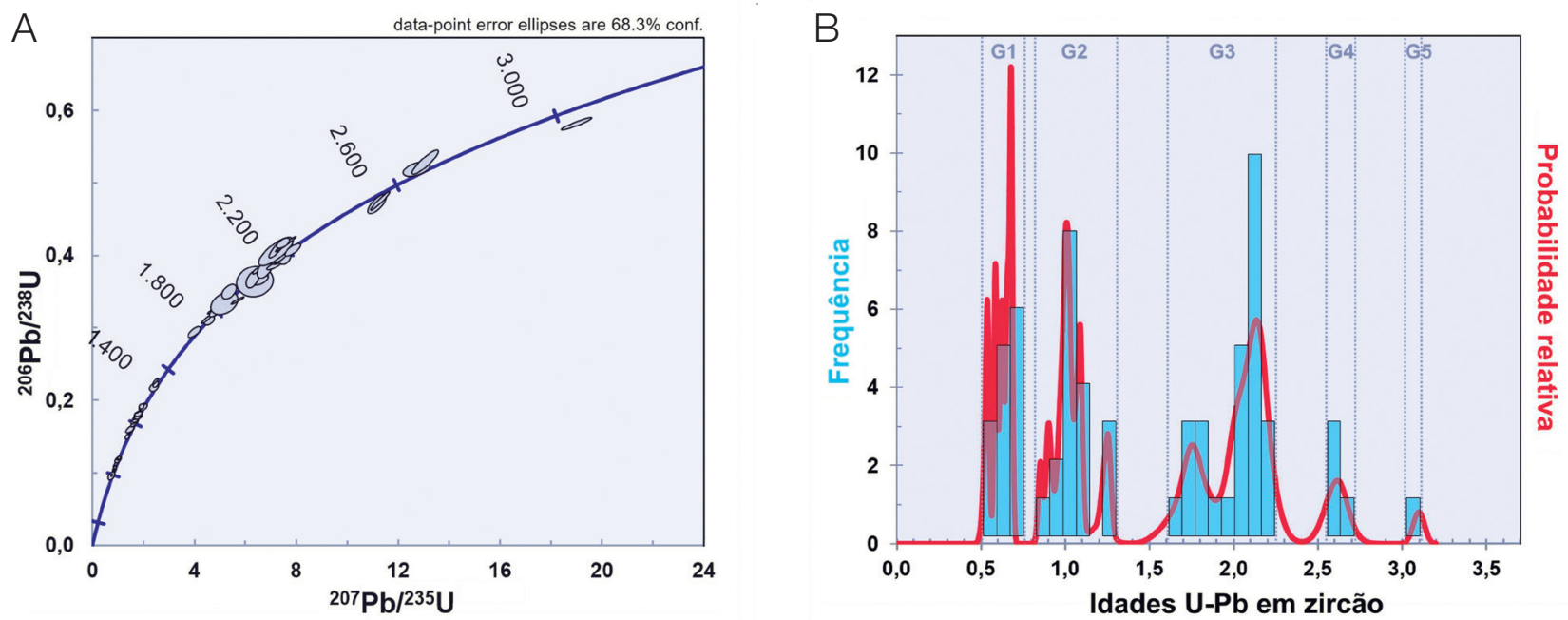

Figura 6. (A) Diagrama concórdia de amostra PDO-01;(B) histograma de densidade e frequência de amostra PDO-01. 
Esses dados sugerem que esse grupo de cristais neoproterozoicos a mesoproterozoicos tem como fontes prováveis: o ortognaisse Serra das Flores (947 Ma; Mendes et al., 2011); o Complexo Cabrobó, datado de $966 \pm 14 \mathrm{Ma}$ (Brito Neves et al., 1995); e granitos indiscriminados mesoproterozoicos (Mendes et al., 2009), que são rochas inclusas nos domínios Pernambuco-Alagoas e Rio Coruripe (Figura 2).

O terceiro e maior grupo (Grupo 3 - G3; Figura 5), com $42,2 \%$ das análises, compreende aqueles cristais de idade paleoproterozoica, variando de 1591 a $2186 \mathrm{Ma}$. Essas idades apresentam uma concordância média de $99,6 \%$. A maior parte desses cristais tem idades riacianas, mas ocorrem também idades orosirianas e estaterianas. O G3 possui dois picos principais na curva de probabilidade (Figura 6): o maior encontra-se aproximadamente em $2150 \mathrm{Ma}$; e o menor, aproximadamente em $1750 \mathrm{Ma}$. As razões $\mathrm{Th} / \mathrm{U}$ dos spots analisados variam de 0,22 a 1,25, com média de 0,65 .

No grupo de idades G3, poucos são os cristais que preservam apenas características de texturas ígneas; a maioria apresenta alguma indicação de sobrecrescimento metamórfico, como texturas sinuosas, sector zoning e interferências em zoneamentos primários anteriores. Há também presença de corrosão nas bordas de cristais. As idades presentes no G3 indicam como possíveis fontes: o Complexo Arapiraca, datado de $1965 \mathrm{Ma}$ (U-Pb; Brito et al., 2005) e o Complexo paleoproterozoico Belém do São Francisco, de idade $2079 \mathrm{Ma}$ (Silva Filho et al., 2002).

O quarto (G4) e quinto (G5) grupos (Figura 5) são compostos por cristais de idades arqueanas. O G4 é composto por idades neoarqueanas, entre 2439 e $2781 \mathrm{Ma}$, com concordância média de 99,3\%. Representam 6,3\% das análises e seu único pico na curva de probabilidade encontra-se a aproximadamente $2600 \mathrm{Ma}$ (Figura 6). O G5 é composto por única amostra de idade mesoarqueana $(3042 \pm 20 \mathrm{Ma})$; essa amostra representa 1,6\% do total e possui concordância de 97,0\%. Para esses grupos (G4 e G5), as razões Th/U dos spots analisados são de 0,51 a 0,84 , com média de 0,57 .

Os quatro cristais arqueanos apresentam estrutura interna metamórfica que se sobrepõe à textura oscilatória primária. O cristal com núcleo mesoarqueano apresenta corrosão em sua borda. Tendo em vista essas idades, esses cristais podem ser provenientes dos Complexos Nicolau Campo Grande e Jirau do Ponciano, pertencentes ao Domo Jirau do Ponciano. Essas unidades foram datadas de forma indireta, por meio de relações observadas em campo (Mendes, 2010). Esses cristais mais antigos preservam, de certa forma, seu formato prismático e são menos arredondados que outros cristais mais recentes, corroborando essa fonte arqueana mais proximal (Figura 2).

Apesar das texturas internas metamórficas supracitadas, presentes em todos os grupos de idades, as razões $\mathrm{Th} / \mathrm{U}$ dos spots analisados são típicas de cristais ígneos (Vavra et al., 1999). Poucos são os spots que desviam desses valores tipicamente ígneos, como no caso das razões $\mathrm{Th} / \mathrm{U}$ que apresentaram valores de 0,9 a 2,0 (Tabela 1). Todavia, esses valores ainda se assemelham muito mais às razões de cristais ígneos do que àquelas atribuídas para cristais metamórficos. É possível que isso ocorra pelo fato de as análises pontuais serem feitas sobre áreas dos cristais em zonas oscilatórias primárias. Assim, tais razões $\mathrm{Th} / \mathrm{U}$ são dados pontuais relacionados ao crescimento ígneo do mineral, e não relacionadas àquelas regiões contendo perturbações metamórficas.

Os trabalhos de Melo (2016) e Melo et al. (2016), que analisaram as composições químicas dos cristais de zircão da Formação Penedo (amostra PDO-01), mostram que a maioria desses cristais apresenta quimismo de cristais de zircão originários de corpos básicos ou com afinidade mantélica, tendo como uma das evidências apresentadas as altas razões $\mathrm{Zr} / \mathrm{Hf}$ (que variam de 17,7 a 101,9). Esses resultados ressaltam a importância das contribuições aportadas pelas unidades que contêm rochas máficas-ultramáficas para a origem dos sedimentos aqui analisados. Dessa forma, no grupo de fontes arqueanas, destaca-se o Complexo Nicolau Campo Grande, que contém protólitos máfico e ultramáfico. Dentre as fontes paleoproterozoicas, o Complexo Arapiraca ganha maior relevância pela presença de complexos ígneos metamáficos-metaultramáficos intercalados a seus paragnaisses. Quanto às fontes mesoproterozoicas, destaca-se o Complexo Cabrobó pelo mesmo motivo - é constituído de biotita gnaisses, com intercalações de metavulcanossedimentares, incluindo metamáficas.

Esses cristais mesoproterozoicos e paleoproterozoicos somam $70,0 \%$ das análises, juntamente com os cristais arqueanos chegam a quase $80,0 \%(76,6 \%)$, e são os que incluem corpos máficos entre seus litotipos. A minoria restante é de cristais cujas fontes apontam para os corpos graníticos brasilianos. Esta poderia ser a mesma minoria de cristais de fontes ácidas descrita por Melo et al. (2016).

\section{CONCLUSÕES}

Os dados geocronológicos U-Pb, de cristais de zircão detríticos da Formação Penedo, permitiram identificar cinco grupos de idades, nomeados de G1 a G5, em ordem cronológica crescente. O G1 (21,9\%) compreende os cristais com idades que variam de 518 a $691 \mathrm{Ma}$; o G2 (28,1\%) possui cristais com idades variando de 840 a $1294 \mathrm{Ma}$; o terceiro e maior grupo (G3) $(42,2 \%)$ compreende idades variando de 1591 a $2186 \mathrm{Ma}$; o G4 $(6,3 \%)$ é formado por idades entre 2439 e $2781 \mathrm{Ma}$; e o G5 (1,6\%) é composto por única amostra, de idade $3042 \pm 20$ Ma.

Para os grupos de idades foram inferidas as quatro fontes: 
1. para o $\mathrm{G} 1$, os granitos neoproterozoicos $(\sim 670 \mathrm{Ma})$ pertencentes aos domínios Pernambuco-Alagoas, Rio Coruripe e Canindé;

2. para o G2, as rochas do Complexo Cabrobó ( $\sim 0,9-1,2 \mathrm{Ga})$;

3. para o G3, as rochas do Complexo Arapiraca com idades paleoproterozoicas $(\sim 1,6-2,2 \mathrm{Ga})$;

4. para o G4 e o G5, as rochas do Complexo Nicolau Campo Grande, do Domo Jirau do Ponciano, de idades neoarqueanas $(\sim 2,4-3,0 \mathrm{Ga})$.

As idades obtidas neste trabalho refletem não apenas a identidade de suas fontes, mas também o complexo histórico de eventos tectônicos registrados na região. Esse contexto inclui diferentes terrenos geológicos e ambiências tectônicas diversas. Idades riacianas $(\sim 2,1 \mathrm{Ga})$ e estaterianas $(\sim 1,7$ $\mathrm{Ga})$ estão sempre presentes em rochas do embasamento da Província Borborema e são evidências de, ao menos, um ciclo de fragmentação e convergência. Os picos de 1,0 e 1,2 Ga relacionam-se a representantes do Ciclo Cariris Velhos, enquanto as idades entre 518 e 691 Ma estariam relacionadas à granitogênese associada ao Ciclo Brasiliano.

Os resultados obtidos neste estudo permitiram inferir sobre as prováveis fontes da seção aflorante PDO-01 da Formação Penedo, BSA. Pondera-se que essas inferências devam ser restritas à seção estudada, de provável idade Rio da Serra.

\section{AGRADECIMENTOS}

À Coordenação de Aperfeiçoamento de Pessoal de Nível Superior (CAPES) pela bolsa de mestrado de Alice Maria Queiroz de Melo. Os autores agradecem o suporte financeiro do Conselho Nacional de Desenvolvimento Científico e Tecnológico (CNPq) e à Fundação de Apoio à Pesquisa e à Inovação Tecnológica do Estado de Sergipe (FAPITEC), processos de números: 308059/2014-0 (CNPq-PQ), 308754/2013-1 (CNPq-PQ), 473013/2012-4 (CNPq-Universal 2013) e 019.203.02538/2009-7 (PRONEX/FAPITEC/CNPq). Aos revisores deste texto expressamos igualmente nossos agradecimentos.

\section{REFERÊNCIAS}

Almeida, G. M. (2016). Estudo de proveniência da sedimentação aptiana aflorante na porção norte da SubBacia de Alagoas. Dissertação (Mestrado). São Cristóvão: Programa de Pós-Graduação em Geociências e Análise de Bacias - UFS.

Amorim, J. L. (1995). Texto explicativo da Folha Arapiraca $S C .24-X-D-V$. Escala 1:100.000. Brasília: Serviço Geológico do Brasil/CPRM.
Araújo, C. E. G., Cordani, U. G., Basei, M. A. S., Castro, N. A., Sato, K., Sproesser, W. M. (2012). U-Pb detrital zircon provenance of metasedimentary rocks from the Ceará Central and Médio Coreaú Domains, Borborema Province, NE-Brazil: Tectonic implications for a long-lived Neoproterozoic active continental margin. Precambrian Research, 206-207, 36-51.

Brito, M. F. L., Mendes, V. A. (2011). Compartimentação Tectônica da Folha Arapiraca. XIII Simpósio Nacional de Estudos Tectônicos e VII International Symposium on Tectonics, 286-289. Campinas: SBG.

Brito, R. S. C., Pimentel, M. M., Wartho, J.-A., Dantas, E. J., Seixas, S. R., Morais, L. C. (2005). Braziliano - Pan-African Sm-Nd and Ar-Ar dating results from the Canindé do São Francisco Gabros - Sergipano Belt-Brazil. V South American Symposium on isotope Geology, 205-207. Uruguai: SSAGI.

Brito Neves, B. B. (1986). Tectonic regimes in the Proterozoic of Brazil. XII Simpósio de Geologia do Nordeste, 235-251. João Pessoa: SBG.

Brito Neves, B. B., Van Schmus, W. R., Santos, E. J., Campos Neto, M., Kozuch, M. (1995). O evento Carirís Velhos na Província Borborema: integração de dados, implicações e perspectivas. Revista Brasileira de Geociências, 25, 279-296.

Campos Neto, O. P. A., Souza-Lima, W., Cruz, F. E. G. (2007). Bacia de Sergipe-Alagoas. Boletim de Geociências Petrobras, 15(2), 405-415.

Cawood, P. A., Nemchin, A. A. (2000). Provenance record of a rift basin: $\mathrm{U} / \mathrm{Pb}$ ages of detrital zircons from the Perth Basin, Western Australia. Sedimentary Geology, 134(3-4), 209-234.

Davison, I., Santos, R. A. (1989). Tectonic Evolution of the Sergipano Fold Belt, NE Brazil, during the Brasiliano Orogeny. Precambrian Research, 45, 319-342.

Fedo, C. M., Sircombe, K. N., Rainbird, R. H. (2003). Detrital zircon analysis of the sedimentar record. In: J. M. Hanchar, P. W. O. Hoskin (Eds.), Zircon: Reviews in Mineralogy and Geochemistry, 53, 277-303. Washington, D.C.: Mineralogical Society of America.

Feijó, F. J. (1995). Bacia de Sergipe e Alagoas. Boletim de Geociências da Petrobras, 8(1), 149-161.

Hallsworth, C. R., Morton, A. C., Claoué-Long, J., Fanning, C. M. (2000). Carboniferous sand provenance in the Pennine Basin, UK: constraints from heavy mineral and detrital zircon age data. Sedimentary Geology, 137(3-4), 147-185. 
Hasui, Y., Carneiro, C. D. R., Almeida, F. F. M., Bartorelli, A. (2012). Geologia do Brasil. São Paulo: Beca.

Johnsson, M. J. (1993). The System Controlling the Composition of Clastic Sediments. In: M. J. Johnsson, A. Basu (Eds.), Processes Controlling the Composition of Clastic Sediments. Geological Society of America, Special Paper, 284, 1-19.

Lana, M. C. (1985). Rifteamento na Bacia Sergipe-Alagoas, Brasil. Dissertação (Mestrado). Ouro Preto: Universidade Federal de Ouro Preto.

Lima, M. M. C. (2013). Caracterização geoquímica, isotópica e geotectônica dos complexos Araticum e Arapiraca, Faixa Sergipana, Alagoas, Nordeste do Brasil. Dissertação (Mestrado). Recife: Programa de Pós-Graduação em Geociências - UFPE.

Link, P. K., Fanning, C. M., Beranek, L. P. (2005). Reliability and longitudinal change of detrital-zircon age spectra in the Snake River system, Idaho and Wyoming: an example of reproducing the bumpy barcode. Sedimentary Geology, $182,101-142$.

Ludwig, K. R. (2012). ISOPLOT v.3.75: a Geochronological Toolkit for Microsoft Excel. Berkeley: Berkeley Geochronology Center.

Mange, M. A., Morton, A. C. (2007). Geochemistry of heavy minerals. Developments in Sedimentology, 58, 345-391.

Matos, R. M. D. (1999). Tectonic and stratigraphic development of the West African and eastern Brazilian Margins: insights from quantitative basin modelling. Geological Society of London, 153, 55-73.

Medeiros, V. C. (2000). Folha SC.24-X: Aracaju NE. Escala 1:500.000. Brasília: PLGB/CPRM.

Melo, A. M. Q. (2016). Caracterização química de zircão (MEV-EDS) aplicada ao estudo de proveniência. Monografia (Graduação). São Cristóvão: Departamento de Geologia - UFS.

Melo, A. M. Q., Rosa, M. L. S., Conceição, H. (2016). Caracterização química de zircão (MEV-EDS) aplicada ao estudo de proveniência. VIII Congreso Uruguayo de Geología, 213-218. Montevidéu: Sociedade Uruguaia de Geologia.

Mendes, V. A. (2010). Texto explicativo da Folha SC.24$X$-D: Arapiraca. Escala: 1:250.000. Recife: CPRM.
Mendes, V. A., Brito, M. F. L., Paiva, I. P. (2009). Folha SC.24-X-D: Arapiraca. Escala: 1:250.000. Recife: CPRM.

Mendes, V. A., Brito, M. F. L., Santos, C. A. (2011). Zona de Cisalhamento Contracional de Palmeira dos Índios. Um possível testemunho do evento Carirís Velhos na Província Borborema. XIII Simpósio Nacional de Estudos Tectônicos e VII International Symposium on Tectonics, 290-293. Campinas: SBG.

Mendes, V. A., Lima, M. A. B., Morais, D. M. F. (2015). Mapa de Recursos Minerais do Estado de Alagoas. Escala 1:250.000. Recife: CPRM.

Mohriak, W. U., Bassetto, M., Vieira, I. S. (1997). Observações sobre a carta estratigráfica e a evolução tectono-sedimentar das bacias de Sergipe e Alagoas. Boletim de Geociências da Petrobras, 11(1/2), 84-115.

Mohriak, W., Bassetto, M., Vieira, I. S. (1998). Crustal architecture and tectonic evolution of the Sergipe-Alagoas and Jacuípe basins, offshore northeastern Brazil. Tectonophysics, 288, 199-220.

Morton, A. C. (1985). Heavy mineral in provenance studies. In: G. G. Zuffa (Ed.), Provenance of Arenites (249-278). Dordrecht: D. Reidel Pub.

Morton, A. C., Claoué-Long, J. C., Berge, C. (1996). SHRIMP constraints on sediment provenance transport history in the Mesozoic Statfjord Formation, North Sea. Journal of the Geological Society London, 153, 915-929.

Morton, A. C., Hallsworth, C. R. (1994). Identifying provenience-specific features of detrital heavy mineral assemblages in sandstones. Sedimentary Geology, 90, 241-256.

Morton, A. C., Whitham, A. G., Fanning, C. M. (2005). Provenance of Late Cretaceous to Paleocene submarine fan sandstones in the Norwegian Sea: Integration of heavy mineral, mineral chemical and zircon age data. Sedimentary Geology, 182, 3-28.

Nascimento, M. S., Góes, A. M., Macambira, M. J. B., Brod, J. A. (2007). Provenance of Albian sandstones in the São Luís-Grajaú Basin (northern Brazil) from evidence of $\mathrm{Pb}-\mathrm{Pb}$ zircon ages, mineral chemistry of tourmaline and palaeocurrent data. Sedimentary Geology, 201(1-2), 21-42.

Neves, S. P. (2015). Constraints from zircon geochronology on the tectonic evolution of the Borborema Province (NE Brazil): Widespread intracontinental Neoproterozoic reworking of a Paleoproterozoic accretionary orogeny. Journal of South American Earth Sciences, 58, 150-164. 
Neves, S. P., Bruguier, O., Bosch, D., Silva, J. M. F., Mariano, G. (2008). U-Pb ages of plutonic and metaplutonic rocks in Southern Borborema Province (NE Brazil): timing of Brasiliano deformation and magmatism. Journal of South American Earth Sciences, 25, 285-297.

Oliveira, E. P., Bueno, J. F., McNaughton, N. J., Silva Filho, A. F., Nascimento, R. S., Donatti-Filho, J. P. (2015). Age, composition, and source of continental arc- and syn-collision granites of the Neoproterozoic Sergipano Belt, Southern Borborema Province, Brazil. Journal of South American Earth Sciences, 58, 257-280.

Oliveira, E. P., Windley, B. F., Araújo, M. N. C. (2010). The Neoproterozoic Sergipano orogenic belt, NE Brazil: a complete plate tectonic cycle in western Gondwana. Precambrian Research, 181, 64-84.

Roback, R. C., Walker, N. W. (1995). Provenance, detrital zircon $\mathrm{U}-\mathrm{Pb}$ geochronomery, and tectonic significance of Permian to Lower Triassic sandstone in southeasthern Quesnellia, British Columbia and Washington. Geological Society of America Bulletin, 107, 665-675.

Santos, A. A. (2015). Proveniência dos sedimentos de porção aflorante do Membro Angico, Formação Riachuelo, da Sub-Bacia de Sergipe. Dissertação (Mestrado). São Cristóvão: Programa de Pós-Graduação em Geociências e Análise de Bacias - UFS.

Schaller, H. (1970). Revisão estratigráfica da Bacia de Sergipe/ Alagoas. Boletim de Geociências Petrobras, 12(1), 21-86.

Silva Filho, A. F., Guimarães, I. P., Luna, E. B. A. (1997). Rb-Sr and $\mathrm{Sm}-\mathrm{Nd}$ studies of the Neoproterozoic juvenile metaluminous Tanquinho complex, PE-AL massif, NE Brazil. Congresso Brasileiro de Geoquimica, n. 2, 466-467. Porto Seguro: SBGq.

Silva Filho, A. F., Guimarães, I. P., Van Schmus, W. R. (2002). Crustal evolution of the Pernambuco-Alagoas Complex; Borborema Province; NE Brazil; Nd isotopic data from Neoproterozoic granitoids. Gondwana Research, 5, 409-422.

Silva Filho, A. F., Van Schmus, W. R., Guimarães, I. P. (2000). High-K calc-alkaline granitoids of ca. 1.Ga TDM alog the limit PE-AL massif/Sergipano fold belt, NE Brazil: a Mesoproterozoic plate. Revista Brasileira de Geociências, 30, 182-185.
Silva Filho, M. A., Acioly, A. C. A., Torres, H. H. F., Araújo, R. V. (2003). O Complexo Jaramataia no contexto do Sistema Sergipano. Revista de Geologia, 16, 99-110.

Sircombe, K. N. (1999). Tracing provenance through the isotope ages of littoral and sedimentary detrital zircon, eastern Australia. Sedimentary Geology, 124, 47-67.

Sircombe, K. N. (2000). Quantitative comparison of large data sets of geochronological data using multivariate analysis: a provenance study example from Australia. Geochimica et Cosmochimica Acta, 64, 1593-1616.

Souza-Lima, W. (2008a). Litoestratigrafia e evolução tectonosedimentar da Bacia de Sergipe-Alagoas: a Formação Penedo (I). Phoenix, 110, 1-4.

Souza-Lima, W. (2008b). Litoestratigrafia e evolução tectonosedimentar da Bacia de Sergipe-Alagoas: a Formação Penedo (II). Phoenix, 111, 1-4.

Souza-Lima, W., Andrade, E. J., Bengtson, P., Galm, P. C. (2002). A Bacia de Sergipe-Alagoas: evolução geológica, estratigrafia e conteúdo fóssil. Aracaju: Fundação Paleontológica Phoenix.

Souza-Lima, W., Borba C. (2008). Litoestratigrafia e evolução tectono-sedimentar da bacia de Sergipe-Alagoas: a Formação Barra de Itiúba (II). Phoenix, 109, 1-4.

Van Schums, W. R., Brito Neves, B. B., Hackspacher, P. C., Babinsky, M. (1995). U/Pb and $\mathrm{Sm} / \mathrm{Nd}$ geochronologic studies of the eastern Borborema Province, NE Brazil. Journal of South American Earth Sciences, 8, 267-288.

Vavra, G., Schmid, R., Gebauer, D. (1999). Internal morphology, habit and U-Th- $\mathrm{Pb}$ microanalysis of amphiboliteto-granulite facies zircons: geochronology of the Ivrea Zone (Southern Alps). Contributions to Mineralogy and Petrology, 134, 380-404.

Vieira, M. M. (1991). Parâmetros controladores da qualidade de reservatórios profundos na Bacia de SergipeAlagoas. Dissertação (Mestrado). Ouro Preto: Escola de Minas - UFOP. 